\title{
Um Canal de Comunicação Inter-FPGA com Módulo de Detecção de Erro
}

\author{
Lucas Melo; Silvio Santana; Silva-Filho, A.G.; \\ Manoel E. Lima \\ Centro de Informática (CIn) \\ Universidade Federal de Pernambuco (UFPE) \\ Recife, PE, Brazil \\ \{ltm3, shcs, agsf, mel $\} @$ cin.ufpe.br
}

\author{
Victor Medeiros, Marcelo Marinho \\ Departamento de Estatística e Informática \\ Universidade Federal Rural de Pernambuco (UFRPE) \\ Recife, PE, Brazil \\ \{victor, marinho\}@ deinfo.ufrpe.br
}

\begin{abstract}
Resumo - Atualmente, sistemas envolvendo múltiplos FPGAs são utilizados em diversas aplicações científicas. Tais sistemas requerem um barramento de dados dedicado para comunicação entre FPGAs, o qual pode ser feito por meio de interfaces do tipo LVDS (Sinalização Diferencial de Baixa Tensão). Outro fator importante é que o roteamento que interconecta os pinos LVDS na plataforma deve ser desenvolvido com precisão para evitar instabilidades na comunicação. Infelizmente, muitas plataformas disponíveis no mercado não observam tais restrições, limitando a taxa de transferência no barramento. Este trabalho apresenta um canal de comunicação bi-direcional inter-FPGAs baseado em uma interface $D D R$ voltado para esse tipo de plataforma. Esta abordagem promove uma comunicação estável entre esses dispositivos sem a utilização de pinos LVDS. Um módulo de detecção de erro também foi desenvolvido para garantir a integridade das transferências e corrigir possíveis erros no barramento. $O$ canal foi validado em uma plataforma comercial. Os resultados de síntese e desempenho também são apresentados nesse trabalho.
\end{abstract}

Keywords - canal de comunicação Inter-FPGAs; comunicação full-duplex; CRC.

\section{INTRODUÇÃO}

Plataformas que envolvem múltiplos FPGAs têm sido alvo de diversas áreas como prototipação de MPSoCs, aceleração de algoritmos e criptografia [1] [2]. Para que esses sistemas possam funcionar de forma eficiente, utilizando paralelamente recursos existentes nos FPGAs, uma comunicação eficiente deve existir entre os FPGAs disponíveis na plataforma. Geralmente esse tipo de comunicação, em FPGAs de última geração, se dá por meio de interfaces tipo LVDS (Sinalização Diferencial de Baixa Tensão) [3]. Esse tipo de sinalização permite o envio de sinais em alta velocidade através de um par diferencial de fios paralelos. A utilização desse recurso permite que a transmissão de dados entre os dispositivos possa ser realizada de forma mais eficiente, possibilitando uma comunicação mais segura contra interferências eletromagnéticas. Esta configuração possibilita que barramentos alcancem taxas de transferências da ordem de 10Gbps com a utilização de dispositivos mais avançados, como é o caso dos FPGAs da família Virtex, da Xilinx [4] e Stratix V, da Altera [5].

Atualmente diversos FPGAs suportam interfaces LVDS e se devidamente alocados na plataforma podem prover uma comunicação de dados a uma alta taxa de transmissão com a utilização de seus transceptores. Entretanto, algumas plataformas disponíveis no mercado não foram projetadas para acomodar os pinos com recursos LVDS do FPGA em suas vias de comunicação, impossibilitando assim, o uso de transceptores LVDS e por conseguinte, prejudicando a implementação de canais de comunicação com alto desempenho. Outros fatores como distância entre trilhas, resistência e capacitância balaceadas são importantes e necessitam ser observados pelos fabricantes desse tipo de plataforma. Uma transmissão de dados realizada sem esses recursos, pode acarretar em erros na transferência de dados quando a taxa de transmissão for alta, uma vez que não há garantia de que será mantida a integridade dos dados. Isso ocorre porque todos os pinos de I/O dos FPGAs, estão, em geral, sujeitos a interferências físicas. Devido a este possível baixo desempenho na transmissão de dados, os sistemas que utilizam estes recursos terão que reduzir a velocidade de seus módulos lógicos para se adequar ao canal e assim diminuir as incidências de erro na comunicação.

Este trabalho apresenta um canal dedicado de comunicação bi-direcional (full-duplex) síncrono, independentemente do uso da interface LVDS. Para garantir uma boa taxa de transmissão o transmissor é baseado em uma interface Double Data Rate $(D D R)$ e para assegurar a integridade dos dados foram desenvolvidos módulos de detecção de erro baseados na geração e verificação Cyclic Redundancy Check (CRC).

O trabalho está organizado como se segue: na Seção II alguns trabalhos relacionados são apresentados; na Seção III é apresentada a plataforma Gidel PROCStarIII utilizada nos experimentos; na Seção IV é apresentada a arquitetura desenvolvida; na Seção V, são exibidos os resultados dos experimentos realizados; por fim, na seção VI a conclusão é apresentada.

\section{TRABALHOS RELACIONADOS}

Nesta seção alguns trabalhos com foco em comunicação inter-FPGAs são apresentados. O trabalho [6] apresenta uma arquitetura para esta finalidade e o trabalho [7] propõe uma solução para otimização da comunicação entre diferentes dispositivos FPGAs.

Em [6] é exibida uma arquitetura para comunicação interFPGA full-duplex com 18 trilhas LVDS de transmissão. A arquitetura é baseada na interface $D D R$ e é composta por um transmissor e um receptor. Os autores demonstram que é possível alcançar taxas de transferência na ordem de $10 \mathrm{Gbps}$ utilizando a abordagem. A arquitetura foi desenvolvida para ser 
implementada em um cluster de alto desempenho (PARAMNet3) [8]. A arquitetura compõe um switch de rede permitindo que o roteamento de pacotes seja realizado em alta velocidade. Cada placa que faz parte do switch é formada por quatro FPGAs Virtex-4 da Xilinx e os Transceptores (Multi-Gigabit Transceivers - MGT's) disponíveis em cada FPGA são utilizados para comunicação com as outas placas do sistema.

O transmissor é formado por uma unidade de controle, buffers I/O LVDS e por um módulo Serializer/Deserializer (SERDES), esses dois ultimos são recursos de I/O já disponíveis nos FPGAs Xilinx Virtex-4. O módulo SERDES é um serializador/deserializador que recebe os dados da aplicação de forma paralela e os serializa. Os buffers de saída LVDS recebem esses dados serializados e implementam a saída em 18 trilhas de pares diferenciais. Cada trilha tem uma taxa de transferência de $625 \mathrm{Mbps}$, somando no total uma taxa de cerca de 10 Gbps.

O receptor tem seu relógio gerado no transmissor, garantido que o funcionamento de ambas arquiteturas estejam sincronizadas. Ele é composto de um módulo de controle, delays, buffers I/O LVDS e um módulo SERDES. Os módulos de delay são responsáveis em introduzir um jitter de 5-10 ps na entrada de relógio proveniente do transmissor. Essa estratégia respeita a janela válida de dados e é necessária para garantir que os sinais sejam recebidos no receptor corretamente. $\mathrm{O}$ relógio utilizado no receptor é de $312.5 \mathrm{MHz}$ e está sincronizado com o transmissor.

A detecção de erro de comunicação é realizada na camada de rede do switch e os autores desenvolveram um test engine para gerar erros no canal de comunicação. Este engine é responsável por testar cada trilha LVDS e duas instâncias foram implementadas em cada FPGA. O ambiente de testes é formado por um processador PowerPC executando uma aplicação que se comunica com a arquitetura por meio de uma interface $U A R T$. É possível configurar parâmetros de teste e visualizar estatísticas na aplicação.

Em [7] é apresentada uma solução para otimização de comunicação inter-FPGAs utilizando um canal de adaptação. $\mathrm{O}$ trabalho demonstra que cada plataforma possui características próprias e que quase sempre, ao migrar-se o projeto para uma outra plataforma, é necessário alterar a arquitetura para se adaptar às mudanças necessárias. Largura do barramento de comunicação, transmissão ponto-a-ponto ou LVDS, são algumas das opções que poderiam ser parametrizadas abstraindo do usuário a necessidade de alterar sua arquitetura. É nesse aspecto que o autor do trabalho se concentra e propõe um canal parametrizável capaz de se auto-adaptar a arquitetura alvo.

Inicialmente é apresentada uma arquitetura base composta basicamente por um módulo de controle, um módulo phy e FIFOs de transmissão $(T X)$ e recebimento $(R X)$. A arquitetura suporta interfaces $S D R / D D R$ e transmissão ponto-a-ponto ou LVDS. Também pode ser utilizado módulos SERDES para serialização/deserialização de dados e é possível definir se a comunicação será unidirecional ou bidirecional. Por fim, a arquitetura permite que a largura do barramento seja ajustável.
O canal de adaptação, chamado chAdapt, é formado por um módulo em hardware que auto-configura a transmissão de acordo com as características da plataforma. Para que isso aconteça, inicialmente uma transmissão de uma sequência de bits ocorre de forma repetida entre transmissor e receptor para identificação de possíveis atrasos na comunicação. Nesse mesmo tempo todos os controles de conexão são otimizados e o alinhamento do relógio é realizado através do ajuste dinâmico de sua fase.

A arquitetura foi testada em diferentes FPGAs utilizando-se como base módulos da plataforma RAPTOR [9]. Esta plataforma permite a adaptação de diferentes módulos reconfiguráveis que são compostos por FPGAs da Xilinx. Os testes foram realizados com os seguintes FPGAs: Spartan-3A, Spartan-6, Virtex-4 e Virtex-5. Diversas combinações foram analisadas a fim de encontrar possíveis otimizações na comunicação. Como resultado, os autores demonstram uma tabela comparativa entre as combinações usadas destacando os percentuais de otimização após a adição do módulo chAdapt na arquitetura. Destacam-se os testes realizados com a comunicação entre dois Virtex-4 e entre Spartan-6 e Virtex-4. Foi possível notar uma melhora significativa na comunicação após a introdução do chAdapt nesses cenários. Os resultados indicam que apesar de não ter sido possível alinhar a largura de barramento para esses testes, o canal implementado oferece um ótimo caminho para a validação dos links de comunicação e identificação de melhores parâmetros de transferência de dados.

\section{PLATAFORMA GIDEL PROCSTARIII}

A implementação do canal de comunicação apresentada neste trabalho foi realizada em uma plataforma PROCstarIII (figura 1) da fabricante Gidel [10]. Ela é composta por quatro FPGAs Stratix III 260E da Altera e possui três bancos de memória: um banco de 512MB DDR2 SDRAM e dois bancos DDR2 que suportam até 32GB.

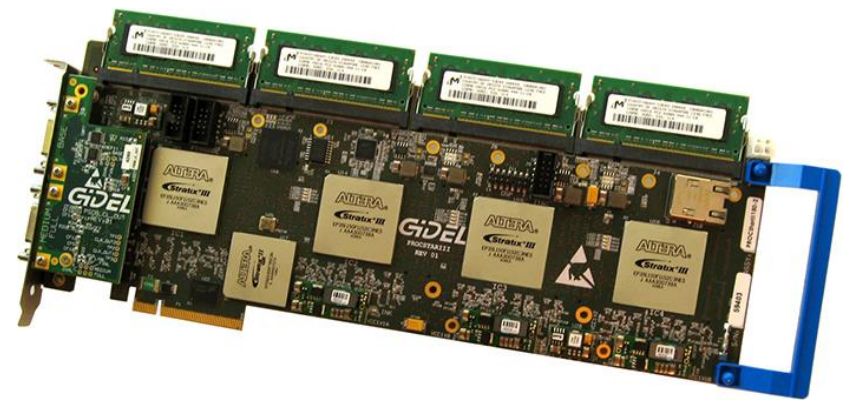

Figura 1. Plataforma Gidel PROCStarIII

Apesar da plataforma disponibilizar quatro FPGAs, ela não possibilita que a comunicação entre eles seja realizada utilizando-se os pares diferenciais disponíveis nesses dispositivos. Isto ocorre porque os pinos dos FPGAs utilizados no projeto da plataforma para serem os pinos de comunicação, ou seja, os pinos que estão diretamente conectados entre os FPGAs adjacentes, são pinos de I/O comuns. Outro aspecto, é que não há garantias relacionadas ao layout da plataforma. Características como resistência, capacitância, distância das 
vias do barramento que interligam os FPGAs não são garantidas, inviabilizando uma comunicação estável. Por estas razões, uma comunicação de alta velocidade pode não ser alcançada. $\mathrm{O}$ barramento local é responsável por conectar todos os FPGAs ao host através do controlador PCIex8. O protocolo de comunicação para este barramento é automaticamente gerado pela ferramenta ProcWizard [11] disponibilizada pela Gidel. O barramento principal conecta todos os FPGAs entre si e tem uma largura de 40 bits.

\section{PROCstarIII.}

A figura 2 apresenta a estrutura interna da plataforma

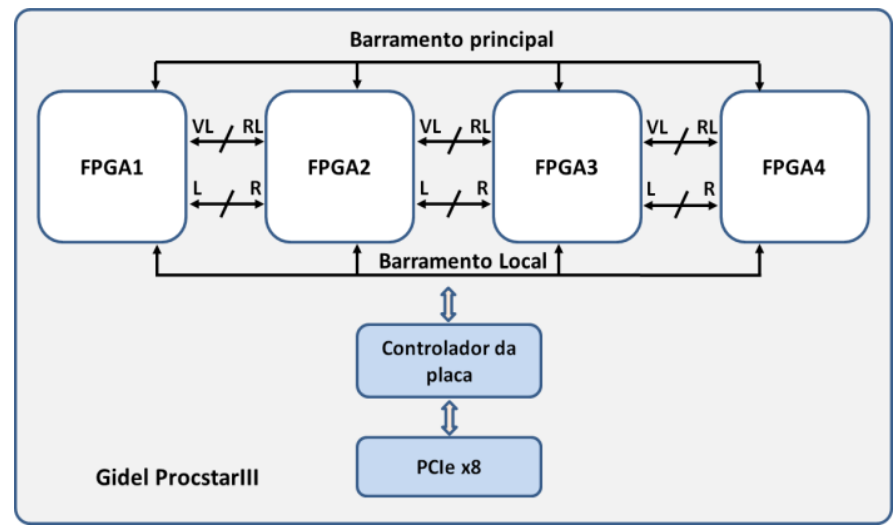

Figura 2. Diagrama da plataforma Gidel PROCStarIII.

Para comunicação de dados, dois barramentos estão disponíveis: o barramento $V L-R L$ e o $L-R$. Cada um deles conecta os FPGAs adjacentes disponíveis na plataforma. O $V L$ $R L$ é um barramento de I/O comum e tem largura de 10 bits. Os sinais utilizados nesse barramento possuem uma tensão de 1.8 V. O $L-R$ possui largura de 100 bits e é também do tipo I/O comum. O barramento $L-R$ além de ser o maior disponível, concentra um único banco de pinos que podem ser utilizados no canal de comunicação. Isto minimiza o impacto referente ao data skew uma vez que suas vias estão alinhadas. Diminui-se assim possíveis problemas de atraso de sinal. Devido a essas características, a arquitetura proposta neste trabalho utilizou este barramento para a implementação do canal de comunicação.

A plataforma também dispõe de conectores JTAG que podem ser utilizados para depuração e conta com conectores do tipo PSDB (PROCStarIII Daughterboard's) que são interfaces de alta velocidade utilizadas para conectar outras placas disponíveis pela fabricante (camera links, interfaces ethernet e etc).

\section{CANAL DE COMUNICAÇÃO}

O sistema de comunicação proposto por esse trabalho é definido como um canal de comunicação paralelo full-duplex de 32 bits, síncrono e bi-direcional. Cada controlador é composto por dois módulos principais: um transmissor e um receptor. A comunicação no canal é sincronizada através de um clock comum. Esse sistema pode ser então acoplado em cada FPGA para permitir a comunicação de dados entre esses dispositivos na plataforma.
Todo o sistema foi idealizado de modo a facilitar a sua adaptação em diferentes projetos. Para que isso fosse possível, foi utilizada uma $F I F O$ de entrada no transmissor e uma $F I F O$ de saída no receptor, tornando o design transparente para o usuário. As adaptações para cada aplicação devem ser feitas através de pequenos ajustes nos parâmetros de entrada e saída de cada $F I F O$.

A Figura 3 exibe o canal de comunicação entre dois FPGAs envolvendo os principais sinais do transmissor e do receptor.

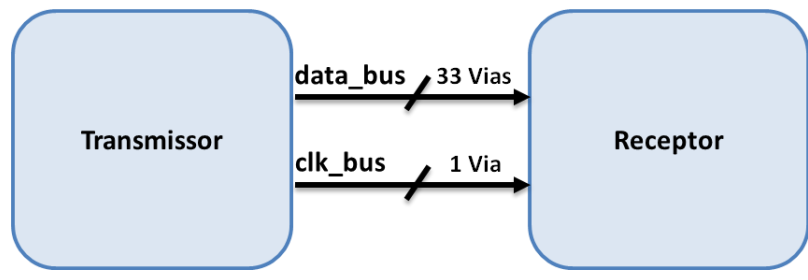

Figura 3. Principais sinais do canal de comunicação.

Uma via única de 33 bits (data_bus) foi definida para a transferência de dados entre os dispositivos. Um bit da via data_bus é destinado a um sinal valid, que indica para o receptor que os dados enviados são válidos e que estes podem ser recebidos e encaminhados para verificação do CRC e, posteriormente, para a FIFO de saída. Sendo assim, o canal de comunicação possibilita uma transferência de dados com uma largura de 32 bits entre os FPGAs.

A via de sinalização crítica clk_bus é destinada a alimentação do sinal de relógio para o receptor. O sinal de relógio (clock) é gerado no transmissor através de uma $P L L$ e encaminhado para o receptor por meio de uma via reservada para esta finalidade. Isso garante que ambos, transmissor e receptor, estejam sincronizados permitindo que o canal de comunicação possa funcionar de forma estável. Os sinais de sincronismo e falha de transmissão que também incorporam o barramento serão discutidos nas próximas seções.

\section{A. Transmissor}

O módulo de transmissão, denominado Transmitter, é responsável por enviar os dados corretamente por meio do barramento. Também é de sua responsabilidade realizar o alinhamento do relógio com a disponibilização dos dados no barramento, aumentando assim o aproveitamento da janela válida, bem como re-transmitir os dados, caso ocorra algum erro em sua transmissão. O transmissor também possui um módulo de geração CRC para os dados enviados. Após a transmissão de um pacote de dados, um checksum que valida esse pacote é enviado pelo barramento para ser verificado no receptor. Caso seja encontrado erros durante a verificação, um pedido de retransmissão é realizado.

Para desempenhar essas tarefas, o módulo Transmitter foi subdividido em cinco módulos: uma FIFO de entrada (FIFO_Input), o Circuito de retransmissão de pacotes, o gerador de CRC (CRC_Gen), a camada física (Trans_PHY) e o Controle do transmissor (Trans_CTRL), conforme esquemático apresentado na Figura 4. 


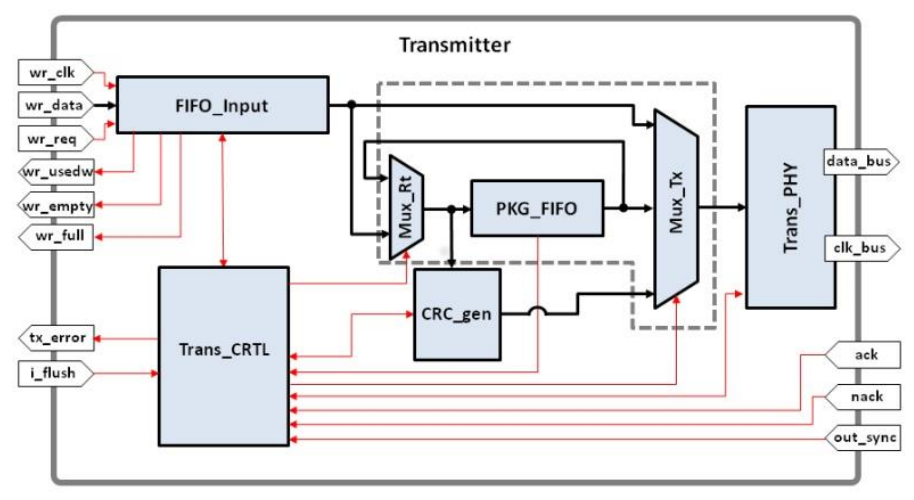

Figura 4. Arquitetura interna do transmissor

A entrada FIFO_Input é um módulo disponível no pacote MegaWizard que acompanha o software de desenvolvimento Quartus II da Altera. Ela tem o objetivo de padronizar a interface do módulo de transmissão com a arquitetura na qual ele será inserido, e de receber os dados a serem transferidos. Sua arquitetura permite que a mesma possa trabalhar internamente com uma frequência diferente da arquitetura ao qual o módulo transmissor está acoplado. Comumente, sua frequência interna é mais alta que a utilizada pela arquitetura, e assim, a velocidade com que os dados são retirados da $F I F O$ pode ser maior que a velocidade com que eles são inseridos.

Para maior flexibilidade no processo de transmissão, tanto a largura dos dados que serão inseridos quanto a profundidade da FIFO são ajustáveis conforme a necessidade do uso por meio de parâmetros de configuração do Transmitter. Por padrão, a largura dos dados corresponde a 128 bits e a profundidade da FIFO é de 256 palavras.

Alguns sinais são disponibilizados pela FIFO de entrada e devem ser utilizados pela arquitetura para a manipulação das escritas de dados na entrada do transmissor. O sinal $w r_{-} c l k$ corresponde à entrada do relógio da arquitetura que fará as escritas de dados serem encaminhadas para o canal de comunicação. Como citado anteriormente, este relógio é independente do relógio interno. O sinal $w r_{-} r e q$ é utilizado para indicar que os dados na entrada $w r \_d a t a$ são válidos e que devem ser escritos na FIFO. O sinal wr_usedw indica para a arquitetura quantas palavras existem internamente na FIFO. Por fim, o sinal wr_empty indica quando a FIFO está vazia e o sinal $w r$ full indica quando a FIFO está cheia. Todos esses sinais foram disponibilizados para que o usuário possa monitorar o estado da FIFO de entrada e ter total controle de escrita de dados para a transmissão.

A comunicação ocorre no barramento por meio de pacotes. Por padrão, o tamanho do pacote a ser transferido é de oito palavras de 32 bits, uma vez que o barramento só suporta transmissões com essa largura de dados. Neste caso, para formar um pacote são necessários dois dados da $F I F O$ de entrada (256 bits). Tomando como base esse exemplo, o transmissor retira os dados da $F I F O$ de entrada e os divide internamente. A primeira divisão ocorre na saída da FIFO de entrada. Por padrão, a saída é de 64 bits. A segunda é realizada dentro do módulo Trans_PHY que divide cada dado de 64 bits em dois de 32 bits. Cada dado do pacote é enviado para o barramento e logo em seguida um checksum é enviado para a verificação da integridade do pacote no receptor. Se houver correspondência durante a verificação do checksum no receptor, o mesmo envia um sinal ack para o transmissor indicando que o pacote foi recebido com sucesso, caso contrário, um sinal nack é enviado e uma retransmissão acontece.

O circuito de retransmissão em destaque na Figura 4, é responsável por manter o pacote de dados a ser transmitido em sua estrutura e, em caso de falha, retransmiti-lo da forma mais rápida possível. Para isso, esse circuito conta com uma FIFO $\left(P K G_{-} F I F O\right)$, que armazena o pacote a ser transmitido, e dois multiplexadores (Mux_Rt e Mux_Tx) que selecionam o caminho correto dos dados a serem enviados. O pacote de dados a ser transmitido, depois de requisitado na FIFO_Input, segue para a camada física (Trans_PHY) através do componente Mux_Tx. Simultaneamente, uma cópia desse pacote é armazenada temporariamente na FIFO de retransmissão $\left(P K G \_F I F O\right)$ por meio do componente $M u x \_R t$. Caso haja algum problema na transmissão, e o sinal nack assumir nível lógico alto, os dados previamente armazenados na $P K G \_F I F O$ são lidos e transmitidos para o receptor via os módulos Mux_Tx e Trans_PHY, respectivamente. Uma retroalimentação garante que esse pacote possa ser retransmitido outras vezes, até atingir o valor de $M A X \_R E T X$, previamente estipulado no projeto. Por padrão esse valor é de 10.

A geração do CRC foi implementada utilizando-se uma ferramenta disponível na web chamada CRC Tool [12]. Essa ferramenta disponibiliza o código de geração CRC tanto em Verilog quanto em VHDL. Ela permite que se escolha o polinômio, o tipo de CRC, a largura dos dados e a linguagem alvo. Escolheu-se o polinômio $p=x^{16}+x^{15}+x^{2}+1$, o padrão "CRC-16/USB Data", largura dos dados de 64 bits, e a linguagem Verilog.

A função gerada pela ferramenta foi adaptada para dentro do módulo CRC_gen que possui uma máquina de estados capaz de gerar o checksum de um pacote de dados. Ao passo que os dados do pacote vão sendo transmitidos, eles também vão sendo analisados pelo $C R C_{\_}$gen que calcula o CRC do pacote e logo em seguida disponibiliza um checksum de 16 bit's para ser transmitido pelo barramento. Cada pacote corresponde a dois dados de entrada na FIFO (256 bits) que depois de divididos internamente tornam-se oito dados para a transferência (32 bits cada). Por padrão, para cada pacote é gerado um código CRC para verificação. É possível também modificar a quantidade de dados do pacote para $4,8,16$ ou 32 palavras.

Através do MegaWizard é possível criar um módulo gerador de CRC. Porém, esse módulo é proprietário, o que inviabiliza o seu uso. Dessa forma, o módulo $C R C_{-} g e n$ foi desenvolvido com as mesmas entradas e saídas do módulo disponibilizado pela Altera, de modo a manter a compatibilidade entre as versões. As Figuras 5 e 6 a seguir, ilustram o protocolo de comunicação desenvolvido para a arquitetura proposta. 


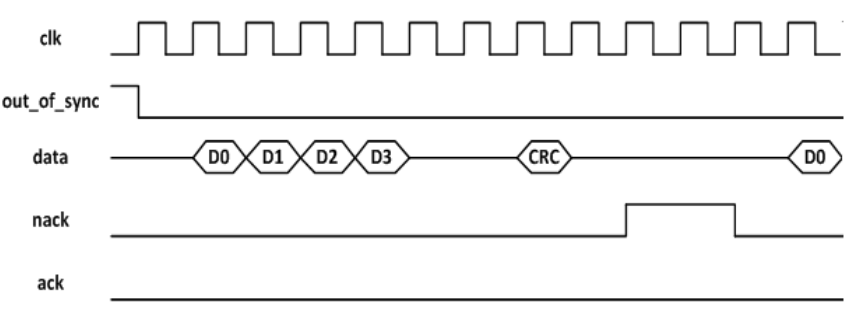

Figura 5. Transmissão com falha de verificação CRC no receptor (nack).

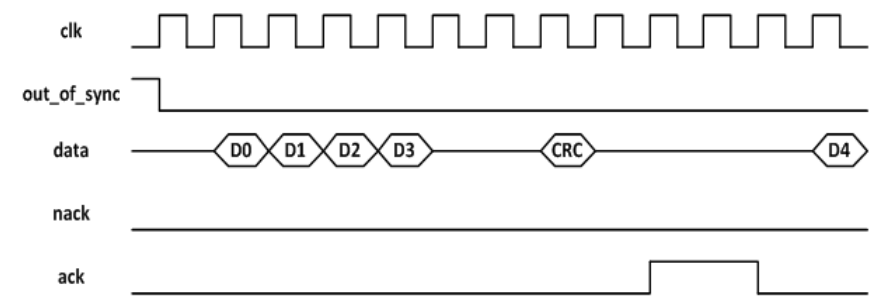

Figura 6. Transmissão realizada com sucesso (ack)

O sinal out_of_sync é proveniente do receptor e tem a finalidade de indicar ao transmissor quando seu relógio interno está sincronizado com o sinal clk_bus. Portanto, a transmissão só ocorre quando esse sinal está no nível baixo.

O módulo Trans_PHY é responsável por gerenciar e encapsular as soluções para o uso dos pinos de I/O do FPGA. $\mathrm{O}$ uso de uma camada física permite futuras alterações no padrão de transmissão sem grandes impactos no projeto.

Os dados ao saírem do Mux_Tx com 64 bits, são quebrados em dois blocos, formando assim a parte alta (data_high) e baixa (data_low). Logo em seguida os dados são transmitidos para o barramento juntamente com um sinal valid.

Seguiu-se o padrão $D D R$ para transmissão [13]. Desta forma, os dados tanto são enviados na borda alta do relógio, quando na baixa, possibilitando uma maior taxa de transferência no canal de comunicação. A Figura 7 apresenta a arquitetura do Trans_PHY.

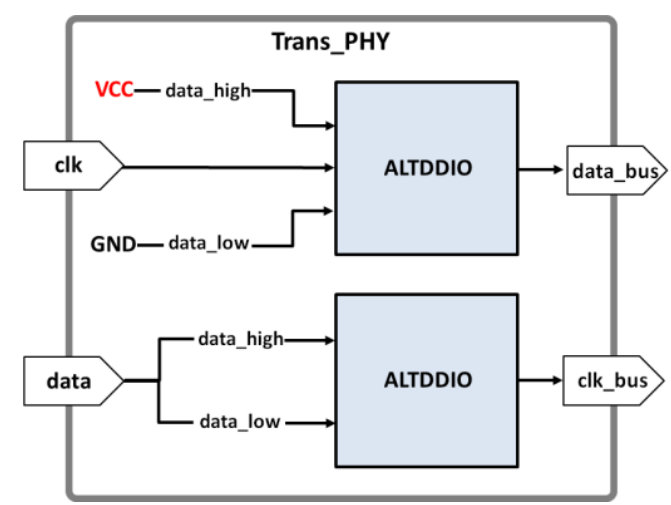

Figura 7. Arquitetura do Trans_PHY

Os módulos ALTDDIO também são gerados a partir da ferramenta MegaWizard. Eles possuem o propósito de gerar dados no padrão $D D R$ e seus registradores internos são implementados em registradores hard silicon, ou seja, diretamente na microarquitetura do FPGA, garantindo menores taxas de skew na saída dos dados.

O primeiro módulo ALTDDIO é utilizado com duas entradas constantes, com data_high ligado ao VCC (nível lógico alto) e data_low ligado ao GND (nível lógico baixo). Essa configuração gera um relógio de saída que está em fase com os dados, ou seja, um alinhamento em borda de subida para o relógio com relação à janela válida de dados.

O segundo módulo $A L D D I O$ é utilizado para envio dos dados, com suas entradas (data_high e data_low) recebendo uma porção distinta dos dados: para data_high, a parte mais significativa do dado (32 bits) e para data_low, a menos significativa (32 bits).

O módulo Trans_CTRL encapsula toda a lógica necessária que gera a sinalização de controle para todos os demais módulos. Essa lógica controla a geração do pacote de dados, o checksum CRC, a entrada de dados por meio da FIFO_Input, e as retransmissões, caso sejam necessárias. Também é de responsabilidade desse módulo indicar para a arquitetura por meio do sinal tx_error se houve algum erro na transmissão dos dados. Este é o caso, por exemplo, do número de retransmissões ter sido atingido. Por fim, $\mathrm{O}$ sinal $i_{\text {fflush }}$ indica ao controle do transmissor o encerramento de entrada de dados na $F I F O$. Dessa forma, é possível completar o pacote de dados com zeros, se necessário, mantendo o padrão de transmissão.

\section{B. Receptor}

O receptor, chamado de Receiver, é responsável por receber os dados através do barramento. Todos os fatores de degradação do sinal que atuarem sobre o canal de transmissão, se existirem, terão seus efeitos refletidos no sinal de entrada desse módulo. Dessa forma, a maior parte da complexidade para corrigir esses efeitos está localizada nele.

A arquitetura interna foi organizada com cinco módulos: camada física (Recv_PHY), duas FIFOs para recebimento dos pacotes (PKG_BUFFER_l e $\left.P K G \_B U F F E R \_2\right)$, verificação do CRC (CRC_chk), FIFO de saída (FIFO_Output) e o Controle (Recv_CTRL) (Figura 8).

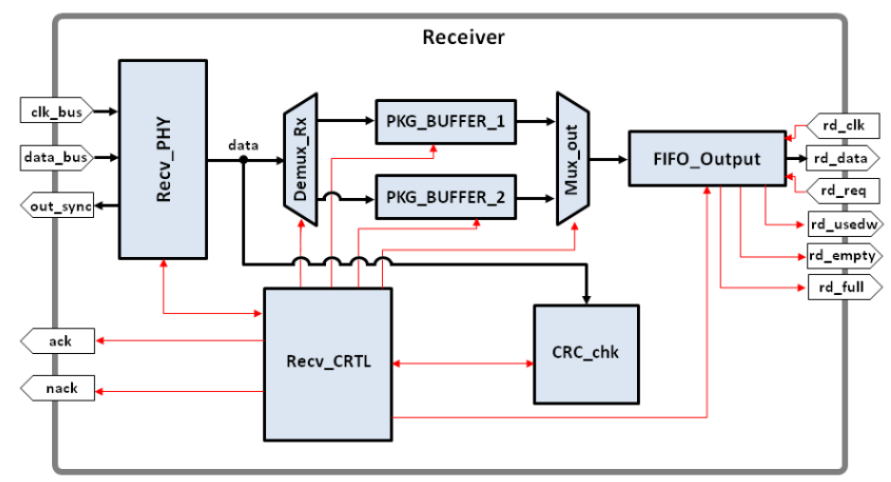

Figura 8. Arquitetura interna do receptor

O módulo Recv_PHY é responsável por receber os dados transmitidos e o relógio proveniente do barramento. Todo o 
circuito que implementa o sincronismo do padrão $D D R$ também está incluído nesse módulo.

Internamente, uma PLL foi implementada para receber o relógio do barramento e alimentar todo o circuito do receptor. A PLL utilizada é um módulo gerado pela ferramenta MegaWizard e é chamada de ALTPLL. Ela é do tipo Source Synchonous, e garante que a geração do relógio feito por ela esteja em total sincronismo com o relógio recebido pelo barramento. A Figura 9 apresenta a arquitetura do Recv_PHY.

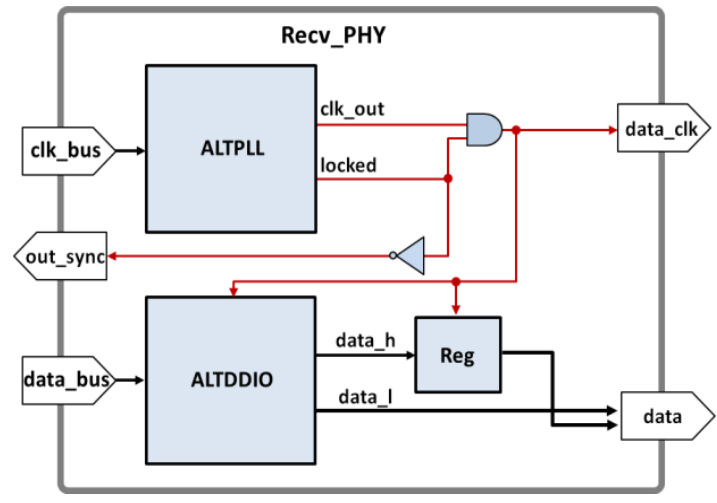

Figura 9. Arquitetura do Recv_PHY

A PLL alimenta o circuito do receptor por meio do sinal data_clk. Um sinal locked é utilizado para indicar quando a PLL atinge o sincronismo com o relógio de entrada. Assim, o sinal out_sync irá garantir que somente as transações possam ocorrer quando ambos transmissor e receptor estiverem sincronizados. A escolha de se inverter esse sinal para enviar ao barramento se deve à intenção de evitar o crosstalking.

A PLL possui um offset de fase de $-90^{\circ}$, proporcionando uma interface de captura de borda oposta (o dado lançado pela borda de subida no Transmitter é capturado pela borda de descida do Receiver) e clock alinhado com o centro da janela de dados válidos (Figura 10).

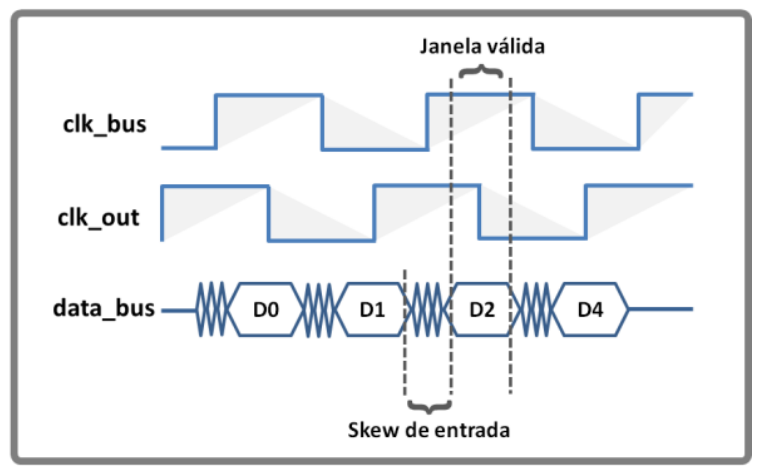

Figura 10. Captura de dados na borda oposta do clock.

A captura com borda oposta proporciona uma inversão na ordem normal de captura dos dados (recebidos pelo módulo ALTDDIO). Para ajustar a ordem correta de recebimento dos dados inverte-se assim a saída data, ou seja, os dados apresentados em data_l devem ser utilizados como a porção alta dos dados que chegam, e os apresentados em data_h devem ser os da porção baixa. O registrador associado ao módulo ALTDDIO é necessário para causar um atraso na saída data_h, uma vez que esse dado é disponibilizado, primeiramente. Assim, a porção alta e baixa do dado recebido segue para a saída data de forma sincronizada.

O circuito responsável por receber os pacotes é composto por um demultiplexador (Demux_Rx), duas FIFOs de pacotes ( $P K G \_B U F F E R \_1$ e $\left.P K G \_B U F F E R \_2\right)$, e um multiplexador (Mux_out). Cada dado ao ser recebido inicialmente é armazenado em PKG_BUFFER_1. Quando um pacote completo é recebido, seu checksum é verificado e caso o pacote seja válido, os dados podem seguir para a FIFO de saída FIFO_Output por meio do Mux_out. Enquanto esse processo de transferência de dados entre $P K G_{-} B U F F E R \_l$ e FIFO_Output ocorre, o Demux_Rx é chaveado para que os próximos dados sejam armazenados em $P K G \_B U F F E R \_2$. O pacote recebido é checado e caso seja válido, os dados são transmitidos para a FIFO_output e o Demux_Rx é chaveado novamente. E possível assim, obter-se um maior desempenho no recebimento dos dados uma vez que não há a necessidade de esperar uma $P K G_{-} F I F O$ ser esvaziada para o recebimento do próximo pacote. As FIFOs PKG_BUFFER_l e $P K G \_B U F F E R \_2$ têm largura de 64 bits e profundidade de 32 palavras cada.

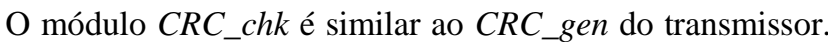
Ele possui a mesma função e é responsável por calcular o CRC dos pacotes que estão sendo recebidos. Ao final da transmissão de cada pacote, o checksum gerado pelo CRC_chk é comparado com o checksum recebido no barramento (gerado pelo $C R C \_$_en). Nessa estrutura, caso a verificação do CRC falhe, os dados são descartados antes de serem inseridos na FIFO de saída e um sinal nack é enviado para o transmissor solicitando uma retransmissão. Caso a verificação do CRC seja positiva, os dados são encaminhados para a FIFO de saída e um sinal ack é enviado para o transmissor solicitando o próximo pacote.

A $F I F O$ de saída é exatamente igual à $F I F O$ de entrada, localizada no Transmitter: possui dois domínios de relógio, profundidade e largura parametrizáveis, e possui funções para ajustar seus parâmetros com base nos dois parâmetros anteriores. Por padrão ela tem uma largura de entrada de 64 bits, largura de saída de 128 bits e profundidade de 256 palavras. O sinal $r d \_c l k$ corresponde à entrada do relógio da arquitetura que fará as leituras de dados. O sinal $r d \_r e q$ é utilizado para solicitar à $F I F O$ uma leitura. O sinal $r d \_u s e d w$ indica para a arquitetura quantas palavras existem internamente. $\mathrm{O}$ sinal $r d$ empty indica quando a FIFO está vazia e o sinal $r d \_f u l l$ indica quando a $F I F O$ está cheia.

O módulo Recv_CTRL encapsula a solução que gera a sinalização de controle para todos os demais módulos, controlando assim a recepção do pacote de dados, a verificação do checksum $\mathrm{CRC}$, a escrita do pacote verificado para a FIFO de saída, o esvaziamento da $F I F O$ de pacotes no caso de erro na verificação do checksum, a requisição de uma retransmissão por meio de um nack, a indicação de uma transmissão realizada com sucesso por meio de um ack e o controle do demux_rx e mux_out.

\section{RESULTADOS}

O canal de comunicação foi testado na plataforma PROCStarIII conectada via barramento PCIex8 a um 
computador Intel Xeon $3 \mathrm{GHz}$ com $4 \mathrm{~GB}$ de memória $D D R$. Diferentes frequências de relógio e tamanhos de pacote foram testados. Cada teste foi realizado considerando-se no máximo uma hora de transferência ininterrupta de dados entre os FPGAs da plataforma.

Os dados a serem transferidos foram gerados por uma aplicação em alto nível e enviados do host para a plataforma via barramento PCIex8. Um controlador de memória específico para as plataformas Gidel (Gidel PROCMultiPort) foi implementado para alimentar o transmissor com os dados encaminhados pela aplicação. Para fins de testes e análises de corretude, os dados recebidos pelo receptor foram encaminhados para o host para que a aplicação pudesse analisar se os dados enviados correspondiam com os dados recebidos.

O tempo apresentado nos resultados refere-se apenas ao tempo efetivo de transmissão de dados no barramento. Neste caso não se está levando em conta o tempo de envio de dados do host para a plataforma, o tempo de transferência de dados entre memória DDR2 (localizada na plataforma) e FPGA transmissor, e o tempo de envio de dados do FPGA receptor para o host.

Foi adotado como base para os testes a quantidade de dados transferidos em uma hora para a configuração de tamanho de pacote de 8 palavras. Com a quantidade de dados transferidos nessa configuração, foi possível refazer os testes variando o tamanho dos pacotes e mensurando o tempo de transferência.

As tabelas I, II, III e IV apresentam os resultados obtidos para as transmissões com frequências de 50, 100, 120 e 150 $\mathrm{MHz}$, respectivamente.

TABELA I. RESULTADOS OBTIDOS COM FREQUÊNCIA DE 50 MHZ.

\begin{tabular}{|c|c|c|c|}
\hline $\begin{array}{c}\text { Tamanho } \\
\text { do Pacote }\end{array}$ & $\begin{array}{c}\text { Taxa de } \\
\text { Transferência (Gbps) }\end{array}$ & $\begin{array}{c}\text { Quantidade de } \\
\text { dados (Gb) }\end{array}$ & $\begin{array}{c}\text { Tempo de } \\
\text { transmissão (s) }\end{array}$ \\
\hline 8 & 0,7 & 316,65 & 3600 \\
\hline 16 & 1,14 & 316,65 & $\sim 2200$ \\
\hline 32 & 1,68 & 316,65 & $\sim 1500$ \\
\hline
\end{tabular}

TABELA II. RESULTADOS OBTIDOS COM FREQUÊNCIA DE 100 MHZ.

\begin{tabular}{|c|c|c|c|}
\hline $\begin{array}{c}\text { Tamanho } \\
\text { do Pacote }\end{array}$ & $\begin{array}{c}\text { Taxa de } \\
\text { Transferência (Gbps) }\end{array}$ & $\begin{array}{c}\text { Quantidade de } \\
\text { dados (Gb) }\end{array}$ & $\begin{array}{c}\text { Tempo de } \\
\text { transmissão (s) }\end{array}$ \\
\hline 8 & 1,4 & 633,30 & 3600 \\
\hline 16 & 2,29 & 633,30 & $\sim 2200$ \\
\hline 32 & 3,37 & 633,30 & $\sim 1500$ \\
\hline
\end{tabular}

TABELA III. RESULTADOS OBTIDOS COM FREQUÊNCIA DE 120 MHZ.

\begin{tabular}{|c|c|c|c|}
\hline $\begin{array}{c}\text { Tamanho } \\
\text { do Pacote }\end{array}$ & $\begin{array}{c}\text { Taxa de } \\
\text { Transferência (Gbps) }\end{array}$ & $\begin{array}{c}\text { Quantidade de } \\
\text { dados (Gb) }\end{array}$ & $\begin{array}{c}\text { Tempo de } \\
\text { transmissão (s) }\end{array}$ \\
\hline 8 & 1,58 & 715,25 & 3600 \\
\hline 16 & 2,6 & 715,25 & $\sim 2200$ \\
\hline 32 & 3,8 & 715,25 & $\sim 1500$ \\
\hline
\end{tabular}

TABELA IV. RESULTADOS OBTIDOS COM FREQUÊNCIA DE 150 MHz.

\begin{tabular}{|c|c|c|c|}
\hline $\begin{array}{c}\text { Tamanho } \\
\text { do Pacote }\end{array}$ & $\begin{array}{c}\text { Taxa de } \\
\text { Transferência (Gbps) }\end{array}$ & $\begin{array}{c}\text { Quantidade de } \\
\text { dados (Gb) }\end{array}$ & $\begin{array}{c}\text { Tempo de } \\
\text { transmissão (s) }\end{array}$ \\
\hline 8 & 1,98 & 894,06 & 3600 \\
\hline 16 & 3,24 & 894,06 & $\sim 2200$ \\
\hline 32 & 4,76 & 894,06 & $\sim 1500$ \\
\hline
\end{tabular}

Todas os testes com as configurações de transmissões apresentadas pelas tabelas foram realizados com sucesso e nenhum erro de transmissão foi detectado.

Para todos os resultados, observa-se um aumento da taxa de transferência de dados quando o tamanho do pacote é incrementado de 8 para 16 palavras, e de 16 para 32 palavras. Isso ocorre por conta dos ciclos de relógio necessários para geração e verificação de CRC no transmissor e receptor. Quanto menor o tamanho do pacote, mais ciclos para geração e verificação de CRC serão necessários, aumentando assim o tempo de transmissão. A Figura 5 exibe um fluxo de transmissão para um tamanho de pacote igual a 4. Nota-se no diagrama que após o envio dos dados alguns ciclos são necessários para o envio do CRC.

De acordo com as tabelas apresentadas, percebe-se que quanto maior a frequência utilizada mais quantidade de dados são transferidos. Os testes realizados com frequência de 150 $\mathrm{MHz}$ obtiveram as melhores taxas de transferências. Para as transmissões com tamanhos de pacotes iguais a 8,16 e 32 foram obtidas taxas de transmissão de 1.98, 3.24, $4.76 \mathrm{Gbps}$, respectivamente.

Apesar dos resultados obtidos apresentarem taxas de transmissão na ordem de Gbps, é importante ressaltar que o barramento para comunicação utilizado possui 32 bits de largura. Para o caso de uma comunicação realizada com frequência de $100 \mathrm{MHz}$ e pacotes de tamanho 8, cada trilha do barramento realiza transferências numa taxa de 44,8 Mbps.

Outro fator que merece destaque é que a mesma arquitetura desenvolvida e testada na PROCStarIII pode apresentar taxas de transmissão diferentes quando implementada em outras plataformas. Características inerentes ao projeto da plataforma podem influenciar diretamente no desempenho da comunicação.

\section{A. Teste de erros na comunicação}

Para testar a retransmissão de pacotes, foi implementado na arquitetura um gerador de erros que tem a função de modificar os dados de saída antes deles seguirem para o barramento de comunicação. Esse gerador foi posicionado na saída do Trans_PHY e altera os bits dos dados de acordo com uma taxa de inserção de erro configurada em milisegundos. Dessa forma, é possível simular erros na transmissão e testar o funcionamento do canal de comunicação nessas condições. Esse tipo de teste garante a funcionalidade do canal de comunicação caso instabilidades ocorram no decorrer de alguma transferência de dados.

O teste foi realizado modificando-se um bit do barramento de comunicação e foi definida uma taxa de inserção de erro de $4 \mathrm{~ms}$. As transferências foram testadas com uma frequência de $100 \mathrm{MHz}$ e tamanho de pacote igual a 8 palavras. A quantidade 
de dados que foram transferidos foi de 633.30Gb, a mesma quantidade utilizada nos testes com $100 \mathrm{MHz}$ em condições normais. A Tabela V apresenta os resultados obtidos.

TABELA V. TESTE DE ERROS COM FREQUÊNCIA DE 100 MHZ E QUANTIDADE DE DADOS TRANSFERIDOS IGUAL A 633.30 GB.

\begin{tabular}{|c|c|c|c|}
\hline $\begin{array}{c}\text { Taxa de } \\
\text { inserção de } \\
\text { erro } \\
\text { (erro/ms) }\end{array}$ & $\begin{array}{c}\text { Quantidade de } \\
\text { erros inseridos }\end{array}$ & $\begin{array}{c}\text { Qnt. de dados } \\
\text { retransmitidos(Mb) }\end{array}$ & $\begin{array}{c}\text { Tempo de } \\
\text { retransmissão } \\
(\mathbf{m s})\end{array}$ \\
\hline $1 / 4$ & 849.871 & 25,93 & $\sim 144$ \\
\hline
\end{tabular}

O número de retransmissões realizadas foi de 849.871 , indicando que esse foi o número de pacotes verificados no receptor que não corresponderam com o checksum enviado. Apesar da grande quantidade de erros, o montante de dados que necessitou ser retransmitido foi de $25,93 \mathrm{Mb}$, não causando grandes impactos em relação ao tempo na comunicação do pacote total de dados.

O tempo necessário para realizar essas retransmissões foi de aproxidamente $144 \mathrm{~ms}$. Esse tempo foi obtido a partir da diferença entre o teste sem inserção de erros e o teste com inserção de erros nas mesmas configurações apresentadas.

Foi possível perceber após as análises dos resultados desse teste que a comunicação foi realizada com sucesso apesar dos erros inseridos propositalmente no barramento. Portanto, uma comunicação estável entre os FPGAs pode ser obtida nessas condições.

\section{CONCLUSÃO}

A utilização de plataformas multi-FPGAs possibilita o aumento de desempenho na execução de aplicações, uma vez que vários dispositivos reconfiguráveis podem ser utilizados para executar uma mesma tarefa ou trabalharem de forma cooperativa. O uso de vários FPGAs em uma mesma plataforma de modo unificado necessita do estabelecimento de um meio de comunicação entre esses dispositivos.

O trabalho apresentado descreveu um canal de comunicação bi-direcional inter-FPGAs baseado em uma interface $D D R$ para transmissão de dados. A arquitetura proposta foi projetada para ser utilizada como uma plataforma reconfigurável, necessitando apenas alguns ajustes de parâmetros do transmissor e do receptor.

Um módulo de detecção de erro baseado no método CRC também foi implementado de maneira a garantir uma comunicação estável. A arquitetura proposta foi testada e validada em uma plataforma PROCStarIII da Gidel.

Nesta plataforma em particular foi possível obter taxas de transferências na ordem de Gbps, destacando-se a transmissão realizada com frequência de relógio de $150 \mathrm{MHz}$, na qual foi possível alcançar taxas de transferências de até 4.76 Gbps. Outro aspecto a ser considerado é que apesar das taxas de transferências obtidas serem satisfatórias, o uso de pinos diferenciais tipo LVDS certamente proporcionariam transferências com taxas mais elevadas. Tomando como referência os dados apresentados em [6], caso fosse possível o uso de 32 trilhas no barramento de comunicação e cada uma com taxas de $625 \mathrm{Mbps}$, seria possível obter transferências de até $20 \mathrm{Gbps}$.

Os FPGAs mais modernos possuem transceptores dedicados para transferências de dados. Dispositivos como o Stratix V da Altera, conseguem atingir taxas de transferências de até 28.05 Gbps. Entretanto, é de fundamental importância que o roteamento das trilhas das plataformas que irão acomodar esses dispositivos seja feito cuidadosamente, evitando assim instabilidades na comunicação.

O canal de comunicação proposto obteve um excelente desempenho visto que é direcionado para plataformas que não possuem recursos avançados como interfaces LVDS e transceptores. Como continuidade deste trabalho, o barramento apresentado será implementado na plataforma mais recente da Gidel, a PROCStarIV. Essa plataforma possui FPGAs Stratix IV da Altera e recursos mais avançados. Espera-se assim que frequências mais altas possam ser alcançadas com o uso do canal de comunicação apresentado.

\section{AGRADECIMENTOS}

Os autores gostariam de agradecer ao Centro de Pesquisa da Petrobras (CENPES), pelo suporte técnico em conceitos de sísmica, a CAPES e a FACEPE pelo suporte parcial financeiro ao projeto.

\section{REFERENCES}

[1] Hammami, O.; Li, X.; Larzul, L.; Burgun, L., "Automatic design methodologies for MPSOC and prototyping on multi-FPGA Platforms," SoC Design Conference (ISOCC), 2009 International , vol., no., pp.141,146, 22-24 Nov. 2009. doi: 10.1109/SOCDC.2009.5423895.

[2] Melnikova, O.; Hahanova, I.; Mostovaya, K., "Using multi-FPGA systems for ASIC prototyping," CAD Systems in Microelectronics, 2009. CADSM 2009. 10th International Conference - The Experience of RDesigning and Application of , vol., no., pp.237,239, 24-28 Feb. 2009.

[3] LVDS Owners's Manual. Texas Instruments. Disponível em: www.ti.com/lit/ml/snla187/snla187.pdf. Acessado: Julho 2013.

[4] Xilinx Inc. Disponível em : http://www.xilinx.com. Acessado: Julho 2013.

[5] Altera Corporation. Disponível em : http://www.altera.com. Acessado: Julho 2013.

[6] Godbole, P.; Batth, A.; Ramaswamy, N., "High speed multi-lane LVDS inter-FPGA communication link," Computational Intelligence and Computing Research (ICCIC), 2010 IEEE International Conference on , vol., no., pp.1,4, 28-29 Dec. 2010.

[7] Inagi, M.; Takashima, Y.; Nakamura, Y., "Globally optimal timemultiplexing in inter-FPGA connections for accelerating multi-FPGA systems," Field Programmable Logic and Applications, 2009. FPL 2009. International Conference on, vol., no., pp.212,217, Aug. 31 2009-Sept.

[8] PARAMNet-3, C-DAC. Disponível em: http://www.cdac.in/html/htdg/products.aspx. Acessado: Julho 2013.

[9] Raptor Modules. Disponível em: http://www.ks.cit-ec.unibielefeld.de/projects/raptor-family/raptor-modules.html. Acessado: Julho 2013.

[10] Gidel PROCStarIII. Disponível em: http://www.gidel.com/PROCStar\%20III.htm. Acessado em: Julho 2013.

[11] Gidel's ProcWizard. Disponível em: http://www.gidel.com/procwizard.htm. Acessado em Julho 2013.

[12] CRC tool. Disponível em: http://www.easics.be/webtools/crctool. Acesado: Julho 2013

[13] DDR Interface Design Implementation. Lattice Corporation. Disponível em: http://www.latticesemi.com/lit/docs/generalinfo/memory_ddr_ interface_wp.pdf. Acessado: Julho 2013. 